\title{
Failure to estimate reliable sex ratios of guanaco from road-survey data
}

\author{
Julieta Pedrana, Alejandro Rodríguez, Javier Bustamante, Alejandro Travaini, and \\ Juan I. Zanón Martínez
}

\begin{abstract}
The guanaco (Lama guanicoe (Müller, 1776)) is a monomorphic polygynous mammal whose adult sex ratio is expected to be balanced or biased towards females. Remarkably male-biased sex ratios of adult guanacos are often estimated from road surveys. We analyzed the distribution of guanaco social groups recorded during road surveys in Patagonia, Argentina, to test the hypothesis that group assignation based upon behavioral traits is not unequivocal and can be biased by survey factors. Guanacos are organized into three social units (family groups, male groups, and solitary males) that are identified by their grouping behaviour. We recorded 992 guanaco groups, and estimated an adult sex ratio of 3.2 males/female. We used generalized additive models to test the null hypothesis that the probability of recording a group as a family group was constant. Alternatively, this probability could decrease when juvenile abundance and (or) detectability was low. The most parsimonious model showed that the probability of classifying a "family" group increased with date, and decreased with group size, distance to the observer, and time of day. Our results do not support the null hypothesis and suggest that road surveys are unsuitable to estimate reliably the social structure or sex ratio of guanaco populations.
\end{abstract}

Résumé : Le guanaco (Lama guanicoe (Müller, 1776)) est un mammifère polygyne monomorphe; on s'attend à ce que le rapport des sexes chez les adultes soit équilibré ou alors qu'il favorise les femelles. On estime souvent des rapports des sexes de guanacos adultes qui favorisent remarquablement les mâles à partir d'inventaires faits sur les routes. Nous analysons la distribution des groupes sociaux de guanacos enregistrée durant des inventaires faits à partir de la route en Patagonie, Argentine, afin de vérifier les hypothèses selon lesquelles l'identification des groupes d'après les traits

comportementaux n'est pas univoque et qu'elle peut être faussée par des facteurs de l'inventaire. Les guanacos sont organisés en trois unités sociales (les groupes familiaux, les groupes de mâles et les mâles solitaires) qui s'identifient par leur comportement de regroupement. Nous avons observé 992 groupes de guanacos et estimé un rapport des sexes de 3,2 mâles/femelle chez les adultes. Nous utilisons des modèles additifs généralisés pour tester l'hypothèse nulle qui veut que la probabilité d'identifier un rassemblement comme un groupe familial reste constante. Autrement, cette probabilité pourrait diminuer lorsque l'abondance de jeunes et(ou) leur détectabilité sont faibles. Le modèle le plus parcimonieux montre que la probabilité d'identifier un groupe "familial" augmente en fonction de la date et diminue en fonction de la taille du groupe, la distance de l'observateur et l'heure du jour. Nos résultats n'appuient pas l'hypothèse nulle et ils indiquent que les inventaires faits à partir de la route sont inadéquats pour une estimation fiable de la structure sociale ou de la proportion des sexes dans les populations de guanacos.

[Traduit par la Rédaction]

\section{Introduction}

The guanaco (Lama guanicoe (Müller, 1776)) is the only large herbivore of the Patagonian steppe, and plays an important ecological role in this large biome of South America (Redford and Eisenberg 1992). Guanacos have long been exploited for fur and meat (Franklin et al. 1997; Baldi et al. 2006), and they also compete with sheep for forage in the arid rangelands of southern Patagonia (Baldi et al. 2001, 2004). Conservation and management issues warrant monitoring of guanaco populations to detect changes in distribution, population size, density, and productivity (Bonino
1988; Merino and Cajal 1993; Saba et al. 1995). Monitoring is frequently based upon road surveys, which are often the only available tool to obtain suitable data at large spatial scales. Consequently, social structure and sex ratio of guanaco populations are also derived from data collected during road surveys (De Lamo et al. 1982; Bonino 1988; Merino and Cajal 1993; Saba et al. 1995). Monitoring sex ratio may help to detect the operation of processes that could selectively reduce survival of a given sex, such as predation, disease, or hunting.

Guanacos are sexually monomorphic (Sarno and Franklin 1999). At short range, visual inspection of the genitals al-

Received 21 January 2009. Accepted 2 July 2009. Published on the NRC Research Press Web site at cjz.nrc.ca on 24 September 2009.

J. Pedrana, ${ }^{1,2}$ A. Travaini, and J.I. Zanón Martínez. Centro de Investigaciones de Puerto Deseado, Universidad Nacional de la Patagonia Austral, Consejo Nacional de Investigaciones Científicas y Técnicas (CONICET), P.O. Box 238, Avenida Prefectura Naval s/n, 9050 Puerto Deseado, Santa Cruz, Argentina.

A. Rodríguez. Department of Conservation Biology, Estación Biológica de Doñana, CSIC, Américo Vespucio s/n, 41092 Sevilla, Spain. J. Bustamante. Department of Wetland Ecology, Estación Biológica de Doñana, CSIC, Américo Vespucio s/n, 41092 Sevilla, Spain.

${ }^{1}$ Corresponding author (e-mail: jpedrana@yahoo.com.ar).

${ }^{2}$ Present address: P.O. Box 238, Avenida Prefectura Naval s/n, 9050 Puerto Deseado, Santa Cruz, Argentina. 
lows sexing (Franklin 1983; Ortega and Franklin 1995; Marino and Baldi 2008), but this is not possible during road surveys (Marino and Baldi 2008). Guanacos exhibit a resource defense polygyny mating system (Franklin 1983). Territorial males defend an area favorable for attracting females. During the breeding season, guanacos may occur in three types of social units (Franklin 1983; Franklin and Fritz 1991; Ortega and Franklin 1995; Bank et al. 2003; Sarno et al. 2003): (1) family groups, made up of one territorial male and several females with their offspring ( $<1$ year old); (2) male groups, formed by nonbreeding, mainly young individuals (>1 year old); and (3) solitary males that seek or defend a territory. Family groups remain together from September to March, and calves are born in November and December after a gestation period of 11.5 months. Most adult females (75\%) are reported to breed (Franklin 1983; Franklin and Fritz 1991; Ortega and Franklin 1995). It is assumed that guanaco social groups can be identified reliably in road surveys by their grouping behaviour. Family groups are distinguished from male groups by the characteristic defensive behavior of the adult territorial male, which tends to stay apart from other individuals, adopting a dominant and vigilant position, while females and juveniles form a compact group (Puig and Videla 1995; Marino and Baldi 2008). The presence of distinctly small juveniles in family groups also distinguishes them from male groups. Males form big loose groups of all age classes (Ortega and Franklin 1995; Puig and Videla 1995), whereas solitary individuals are thought to be mature males (Ortega and Franklin 1995). Given these assumptions, the population sex ratio can be estimated from the sex composition of these social groups.

Adult sex ratios of polygynous mammals are characterized by an imbalance against males despite sex ratios at birth approaching parity (Clutton-Brock 1989). The comparatively lower survival of males that generates this pattern has been attributed to higher growth rates associated with increased energy demands, as well as to the costs of dispersal and intrasexual competition for access to females (Emlen and Oring 1977; Clutton-Brock et al. 1982; Clutton-Brock and Iason 1986). Accordingly, the sex ratio of adult guanacos should be slightly biased toward females (Clutton-Brock 1991). However, remarkable deviations of sex ratio toward males have been reported from road-survey data (as much as 2.5 males per female; e.g., Merino and Cajal 1993; Saba et al. 1995).

Male-biased sex ratios in adult guanacos could be explained by a number of reasons: (i) a true deviation from theoretical predictions; (ii) a nonrandom distribution of social groups in relation to roads; and (iii) frequent group misclassification during road surveys because sex ratio is derived from the classification of observations into social groups. Family groups without juveniles, or without a male showing a clear defensive behavior, could be left unclassified or erroneously assigned to male groups. If errors in social-group assignment during road surveys were not random, i.e., certain social groups were misclassified more frequently than others, then a systematic bias in the estimated population sex ratio could arise. Alternatively, group composition may not be as rigid as previously reported (Franklin 1983), or may not be unequivocally identified through behavioral traits.

In the absence of independent estimates of guanaco sex ratio, it is impossible to test estimates derived from road surveys. However, it is possible to test whether classification of social groups is influenced by survey variables, and this was the aim of our study. We hypothesized that guanaco groups observed in road surveys cannot be unequivocally assigned to social groups based on behaviour, and that small family groups without juveniles will be easily misclassified. If this is true, situations that reduce juvenile occurrence or detectability will increase the probability that a family group will be classified as a male group. Specifically, we expected that the frequency of recording a group as a family group will (i) increase with time from the onset of the birthing season, as a higher proportion of females will have given birth late in the season; (ii) decrease around dusk, when visibility is poorer than at other times of the day; (iii) decrease with distance to the observer, as juveniles may be harder to see than adults at long distances; and (iv) will decrease as topography becomes more complex, because the chances of juveniles being hidden may be higher in rugged terrain. We also checked whether the probability of recording a family group was constant among observers, because social group's assignment based on behavior could be subjective to some degree. We controlled for the effect of group size because male groups tend to be larger than family groups (Puig and Videla 1995), and larger groups could be detected at longer distances.

Finally, social-unit assignation may be in practice based on juvenile presence rather than on group behavior, as the latter may be loaded with subjective appreciations. So, we hypothesized that the variables which increase the probability that a group was classified as a family group should be the same as those increasing juvenile detectability within family groups. To test this hypothesis, we examined the relationship between variables influencing group assignation and the juvenile/female ratio within family groups.

\section{Material and methods}

\section{Study area}

This study was conducted in Santa Cruz Province, southern Argentina $\left(46^{\circ} \mathrm{S}-53^{\circ} \mathrm{S}, 65^{\circ} \mathrm{W}-73^{\circ} \mathrm{W}\right)$, which belongs to the Patagonian Phytogeographic province, Central District (Cabrera 1976). The area is dominated by hills and open habitats characterized by a mixed steppe of grass and shrubs, rarely exceeding $0.5 \mathrm{~m}$ high (Soriano 1956; Rial 2001). The Andean mountains extend $2000 \mathrm{~km}$ north to south and delimit the western border of the province. Nothophagus forest covers the slopes of the Andes, whereas lowlands are dominated by shrub-steppe. The climate is dry and cold with strong westerly winds. Mean annual temperature is $17{ }^{\circ} \mathrm{C}$, and the mean annual precipitation ranges from $125 \mathrm{~mm}$ in the east to $500 \mathrm{~mm}$ in the west.

Santa Cruz is one of the largest provinces in Argentina, with a surface of $245865 \mathrm{~km}^{2}$ and a population density of $<1$ inhabitant $/ \mathrm{km}^{2}$. It contains $9000 \mathrm{~km}$ of national and provincial roads. Approximately $10 \%$ of these roads are paved, whereas the remaining are secondary or dirt roads. Traffic density is very low ( $<5$ vehicles/day) on most roads. 
Table 1. Number of sightings, number of individuals, and group size of social units of guanaco (Lama guanicoe).

\begin{tabular}{lllll}
\hline & & \multicolumn{2}{c}{ Group size } \\
\cline { 4 - 5 } Social unit & No. of sightings & No. of individuals & Mean & SD \\
\hline Male groups & 296 & 3282 & 11.1 & 10.2 \\
Family groups & 204 & 1959 & 9.6 & 5.1 \\
$\quad$ Males & 204 & 204 & 1 & \\
Females & 204 & 1202 & 5.9 & 3.6 \\
Juveniles & 191 & 550 & 2.9 & 2.15 \\
Solitary males & 324 & 324 & 1 & \\
Undetermined groups & 168 & 403 & 2.4 & 0.6 \\
Total & 992 & 5965 & 6.0 & 4.5 \\
\hline
\end{tabular}

\section{Sampling design}

As part of a study on the spatial distribution and abundance of guanaco populations in Santa Cruz, we surveyed guanacos along road transects during two austral springsummer seasons (November 2004 - February 2005 and December 2005 - January 2006). Before conducting field studies, we stratified the study area into 12 regions based on two environmental variables: mean NDVI (normalized difference vegetation index) and mean slope (for details see Travaini et al. 2007). We used mean NDVI because primary productivity could be an important driver of guanaco occurrence, and mean slope because detection could be affected by terrain irregularity. Using vector data cover of road distribution, we randomly selected road segments that added up to $4500 \mathrm{~km}$ for the first austral spring-summer year. To guarantee that all strata were properly sampled, $1500 \mathrm{~km}$ were equally distributed among survey strata (125 km on each strata) and $3000 \mathrm{~km}$ were distributed proportionally to the area of each stratum (Travaini et al. 2007). During the second springsummer year, we surveyed a total of $3500 \mathrm{~km}$ of new road segments, which means that about $90 \%$ of available national and provincial roads in Santa Cruz were surveyed.

\section{Field surveys}

Guanaco surveys were performed from vehicles driven at a maximum speed of $40 \mathrm{~km} / \mathrm{h}$ by two observers. We selected this methodology because of the open nature of the steppe environment, the low density of wildlife, and because it allows more area to be covered in a fixed amount of time compared with other methods (Travaini et al. 2007).

For each sighting, we stopped the vehicle, recorded group size, and assigned the group to a social unit type. We classified as family groups those in which a single guanaco stayed well apart from the other individuals that tended to group close together. Detection of one or more juveniles also led us to record a family group. In family groups, we assumed that all adult-sized individuals, except one, were females. Loose groups (e.g., guanaco groups in which individuals were randomly distributed but in sight view of each other) without juveniles were considered male groups. Groups without juveniles that did not clearly conform to the "one isolated individual - compact group" or to the "loose group" pattern were classified as undetermined. Solitary individuals were classified as males (Franklin 1983; Ortega and Franklin 1995; Young and Franklin 2004). We measured our distance to the animal or to the center of the group with a laser range finder (Leica LRF 1200 Rangemaster), as well as the angle of the animal relative to our bearing. We obtained our bearing relative to north from the inertial compass of a GPS unit (global positioning system, Garmin GPS MAP 76CS). Guanaco sightings were collected in a PDA (personal digital assistant, Palm Tungsten T3) synchronized with the GPS, which was used to record the trajectory and location of the survey track, as well as the date and time of each observation. Distance and angle in relation to North allowed us to obtain the actual positions of guanacos.

\section{Analyses}

We evaluated six predictors as potential determinants of juvenile occurrence and juvenile detectability. Date, as the number of days since 1 September, was used as a predictor of juvenile occurrence. Predictors of juvenile detectability included three variables related with visibility: slope, distance to the observer, and time of day. The slope was computed as the mean slope in degrees in a $1 \mathrm{~km}$ pixel estimated from a digital elevation model obtained from the Shuttle Radar Topography Mission (SRTM; details of this product are available from http://seamless.usgs.gov). Observer and group size were included as covariates in the models. Observers could differ in their subjective assessment of behavioral criteria and in their ability to detect juveniles in the group. Group size was expected to vary among social groups and could affect group detectability.

We fitted generalized additive models (GAMs; Hastie and Tibshirani 1990) to the probability of a guanaco group being classified by the observer as a family group, using binomial error and logistic link (analogous to a logistic regression: 1 = family group, $0=$ male group) with the S-Plus 2000 software (MathSoft 1999). The predictors for the models were selected from the initial set by a backward-forward stepwise procedure starting from a full model that included all relevant predictors. Predictors were included initially in the models as smoothing splines with three degrees of freedom. Each predictor was tested for significance and simplification (reducing the degrees of freedom of the spline up to a linear model), retaining those that resulted in the largest, significant change in deviance. Only variables significant at the 5\% level were retained in the models. When the residual deviance was substantially larger than the residual degrees of freedom in the final model, indicating significant overdispersion, we used a $F$ test instead of the $\chi^{2}$ test to compare the original and the simplified models (Crawley 2002). 
Fig. 1. Frequency distribution of group sizes for different social units of guanaco (Lama guanicoe). Solitary males are represented as male groups of size 1 .

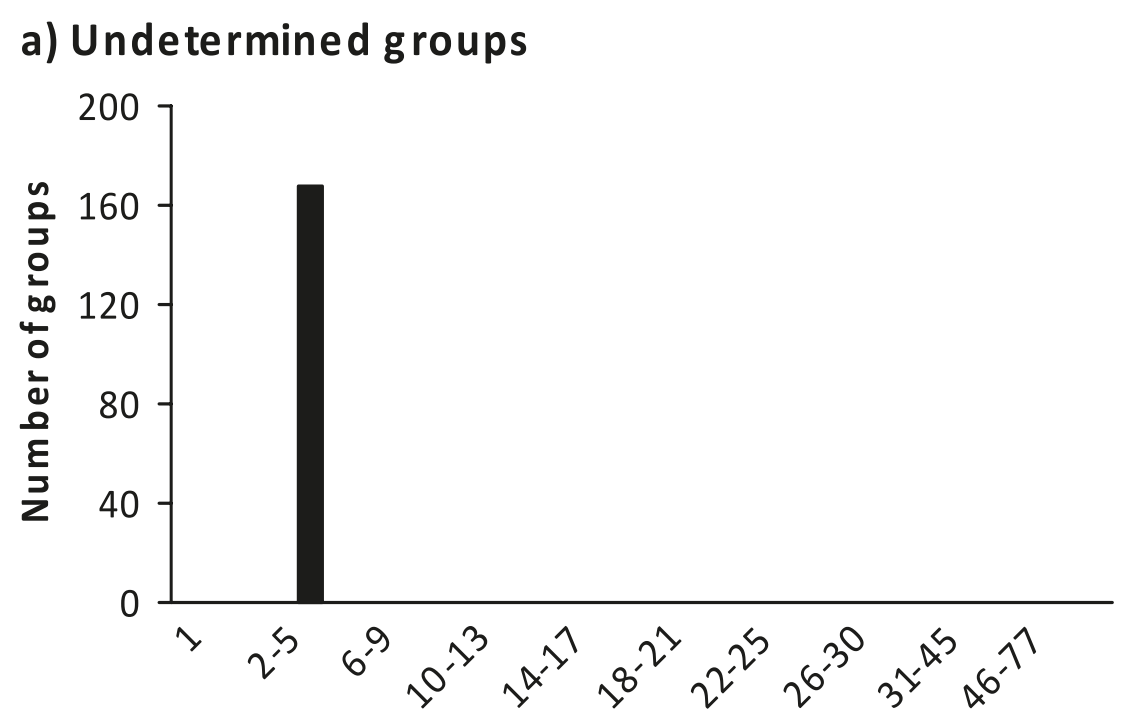

\section{b) Male groups}

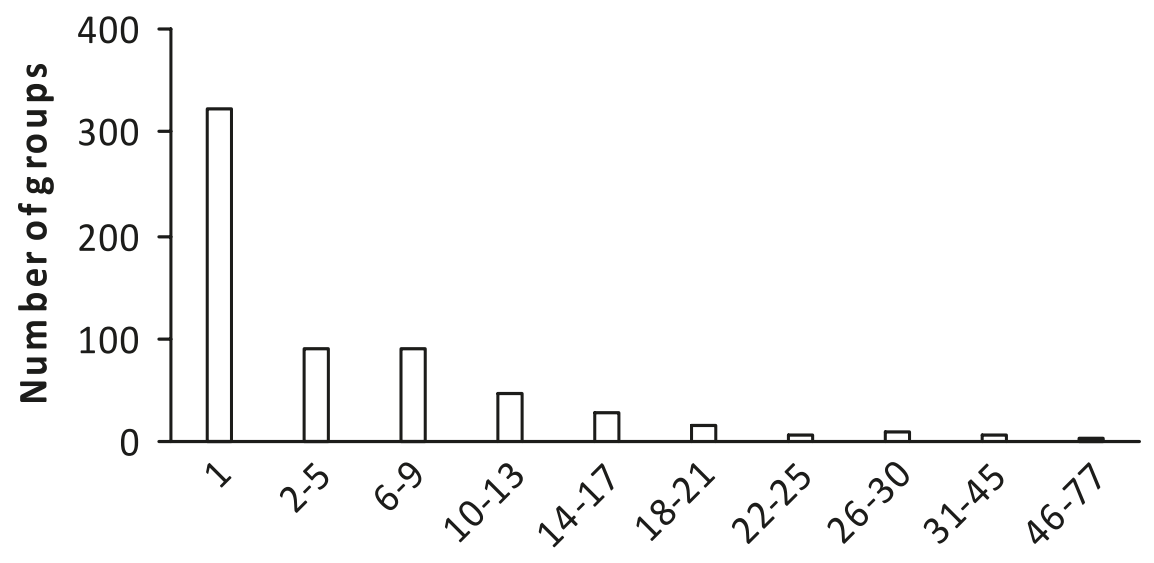

\section{c) Family groups}

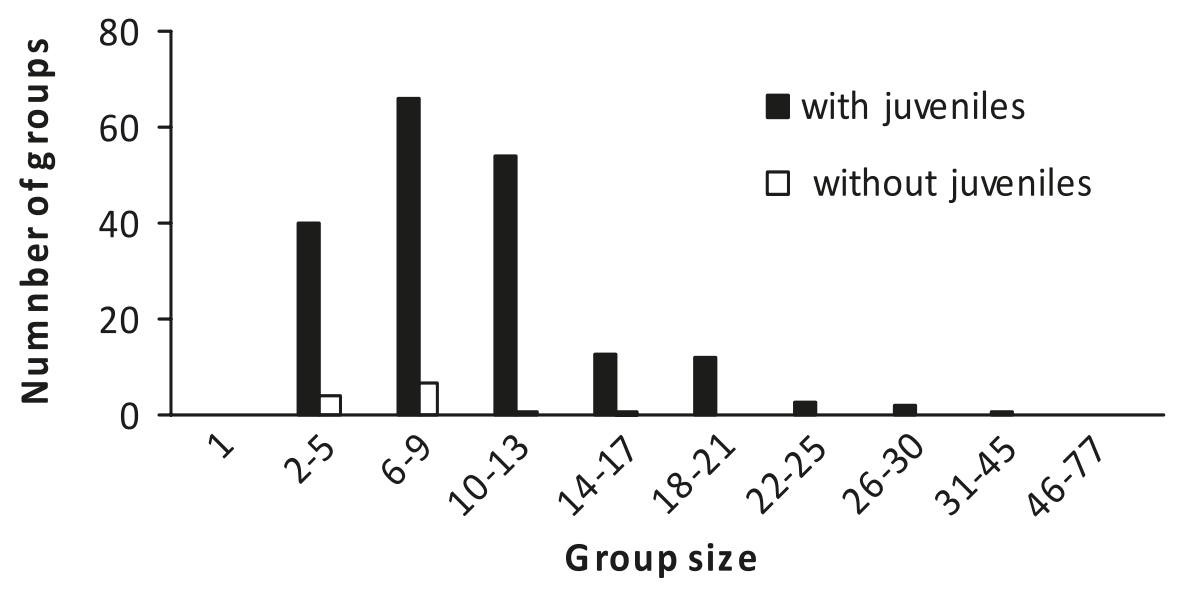

We used the same procedure to analyze which variables influenced the juvenile/female ratio within family groups. We fitted a GAM model with the number of juveniles in the numerator and the number of females in the denominator as the response variable using binomial errors and a logistic link. The predictors for the model were selected from the same initial full set by a backward-forward stepwise procedure. 
Table 2. Explained deviance of the null and the final models of the probability of assigning a group of guanaco (Lama guanicoe) to a family group.

\begin{tabular}{llrrrrc}
\hline Model & Coefficient & SE & df & Deviance & \multicolumn{1}{c}{$F$} & $P$ \\
\hline Null & & 454 & 620.26 & & \\
Final & & & 10 & 56.76 & & \\
Final (simplified to linear terms) & & & 3 & 42.92 & & \\
$\quad$ Date & 0.005 & 0.003 & 1 & 9.21 & 4.21 & $<0.001$ \\
Time of day & -0.09 & 0.02 & 1 & 15.35 & 13.30 & $<0.001$ \\
Distance & -0.0005 & 0.003 & 1 & 18.36 & 3.85 & 0.05 \\
\hline
\end{tabular}

Note: The final model contains splines with $3 \mathrm{df}$ for group size, date, and distance, whereas time of day is fitted as a linear term. The significance of predictors retained in the final model is shown once simplified to linear terms.

Fig. 2. Mean partial effect (solid line) and standard error of the partial effect (broken lines) for predictors retained in the final generalized additive model (GAM) of the probability of classifying a group of guanaco (Lama guanicoe) as a family group.
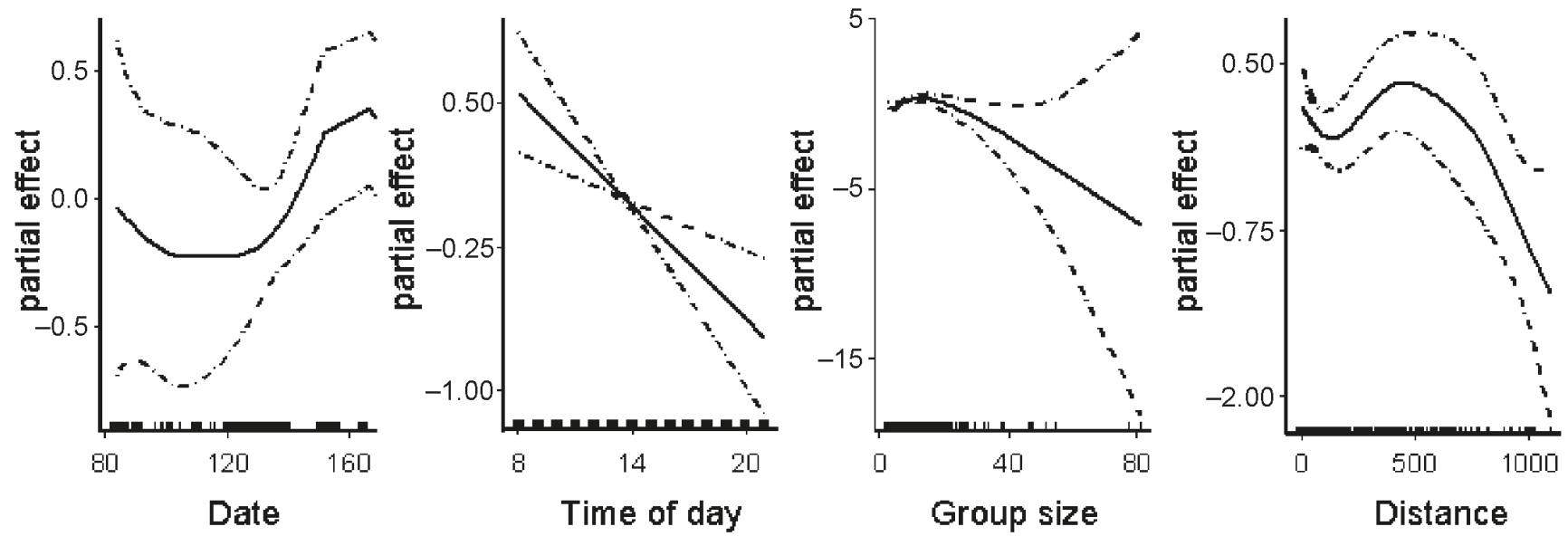

Fig. 3. Frequency distribution of family groups (open bars) and male groups (solid bars) of guanaco (Lama guanicoe) in relation to distance to the observer.

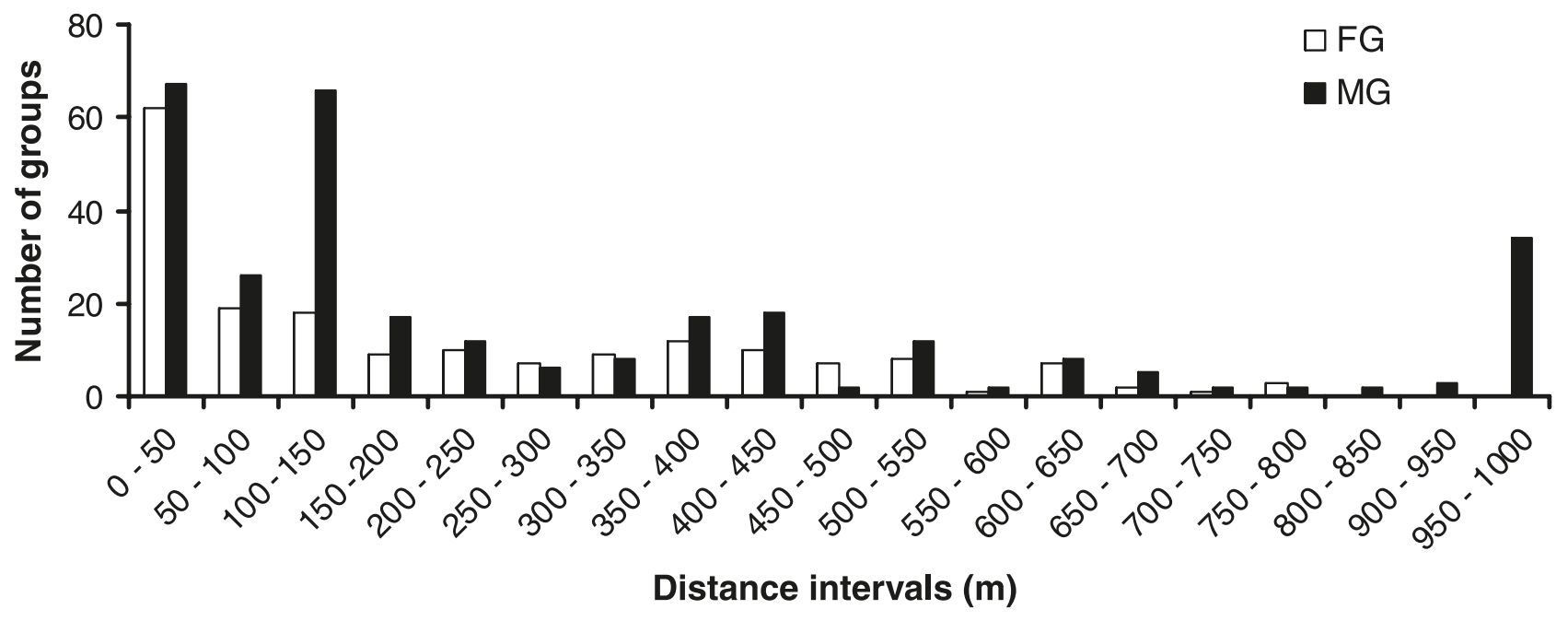

\section{Results}

\section{Frequency of guanaco social units and group sizes}

We recorded 992 guanaco groups that made a total of 5965 individuals (Table 1). Male groups accounted for $30 \%$ of sightings, $21 \%$ were assigned to family groups, $16 \%$ were considered undetermined groups, and $33 \%$ were solitary individuals. Estimated sex ratio for the overall guanaco population was 3.2 males/female (3810 males / 1202 females), departing remarkably from the expected theoretical bias to wards females expected in a polygynous mammal. Out of 992 contacts with guanaco groups, 500 were classified either as family or male groups. We excluded solitary males and undetermined groups from further analyses.

All undetermined groups recorded in this study were groups of 2-5 individuals (Fig. 1a), male groups had a highly variable size (2-77 individuals; Fig. $1 b$ ), and family groups varied between 2 and 45 individuals. Juveniles were detected in most family groups (93.6\%; Fig. 1c). 
Fig. 4. Mean partial effect (solid line) and standard error of the partial effect (broken lines) for predictors retained in the final generalized linear model (GLM) of the probability of classifying a group of guanaco (Lama guanicoe) as a family group once simplified to linear terms.
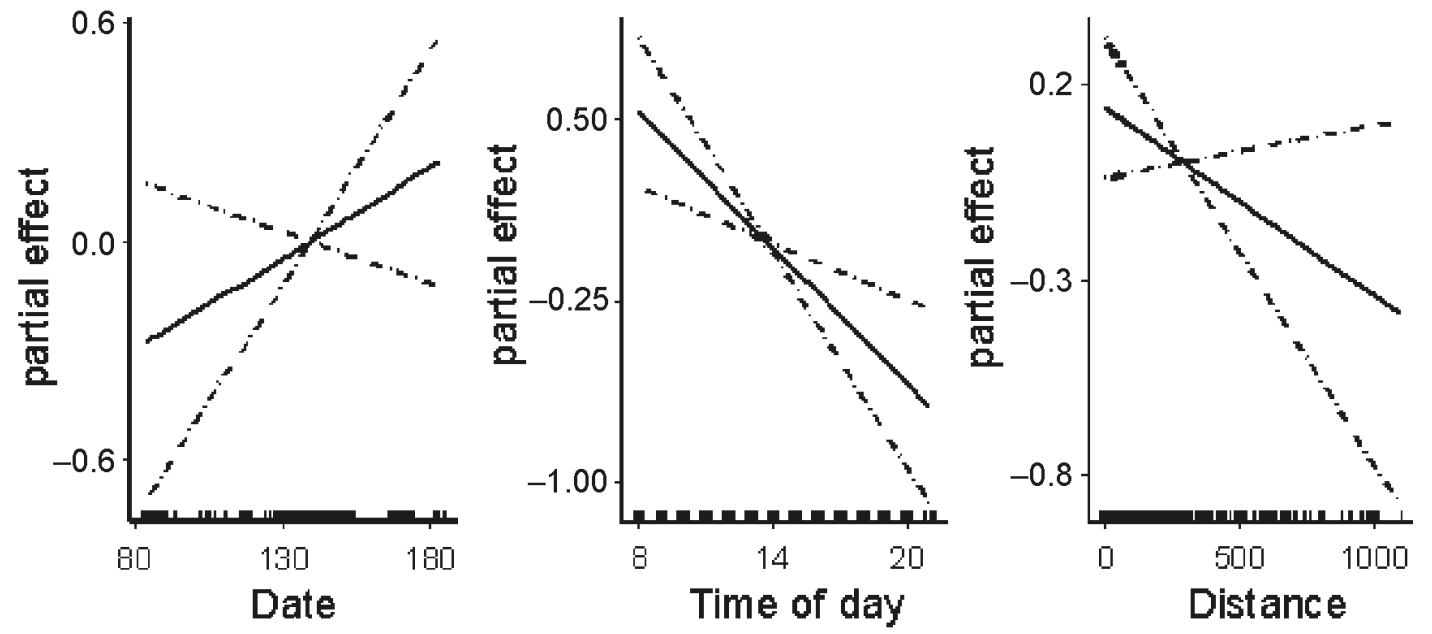

Fig. 5. Mean partial effect (solid line) and standard error of the partial effect (broken lines) for predictors retained in the final generalized additive model (GAM) of juvenile/female ratio of guanaco (Lama guanicoe).
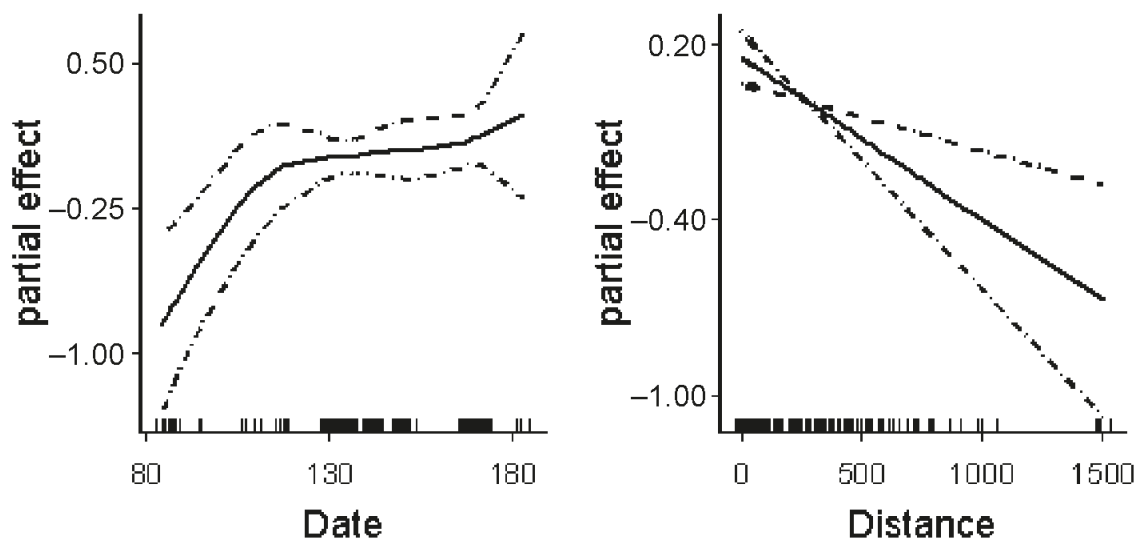

Table 3. Explained deviance of the null and the final models of the juvenile/female ratio in family groups of guanaco (Lama guanicoe).

\begin{tabular}{lcrrrrl}
\hline Model & Coefficient & SE & df & Deviance & $F$ & $P$ \\
\hline Null & & & 192 & 196.08 & & \\
Final & & & 4 & 29.28 & & \\
Final (simplified to linear terms) & & & 2 & 23.04 & & \\
$\quad$ Date & 0.0068 & 0.002 & 1 & 13.4 & 6.88 & $<0.001$ \\
$\quad$ Distance & -0.0007 & 0.0002 & 1 & 9.64 & 3.79 & $<0.001$ \\
\hline
\end{tabular}

Note: The final model contains splines with 3 df for date, and distance is fitted as a linear term. The significance of predictors retained in the final model is shown once simplified to linear terms.

\section{Factors affecting assignation of groups to social units}

The most parsimonious model for the probability of classifying a group of guanacos as a family group included the predictors date, group size, distance, and time of day (Table 2). This model indicated that the probability of contacting a family group increased with survey date, and decreased with group size, time of day, and distance to the observer (Fig. 2). Furthermore, the distribution of family groups decreased faster with the distance to the observer than the distribution of male groups (Fig. 3).

To test if the increase or decrease was statistically significant, we simplified all predictors in the model to linear terms. There was a significant increase with date $\left(F_{[1,498]}=\right.$ $4.21, p<0.001)$, and significant decreases with distance to the observer $\left(F_{[1,498]}=3.85, p=0.05\right)$ and with time of day $\left(F_{[1,498]}=13.30, p<0.001\right)$, while the effect of group size was not significant $\left(F_{[1,498]}=1.44, p=0.23\right.$; Fig. 4).

The juvenile/female ratio increased nonlinearly with survey date, and decreased linearly with the distance to the observer (Fig. 5). These effects were statistically significant (Table 3). When the model was simplified to linear terms, the significant increase of the juvenile/female ratio with date was confirmed (Fig. 6; $F_{[1,189]}=6.88, p<0.001$ ). 
Fig. 6. Mean partial effect (solid line) and standard error of the partial effect (broken lines) for predictors retained in the final generalized linear model (GLM) of the juvenile/female ratio of guanaco (Lama guanicoe) once simplified to linear terms.

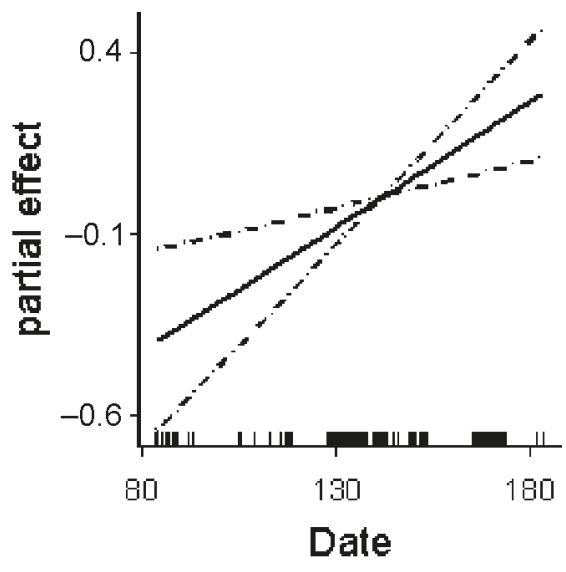

\section{Discussion}

Our results did not support the null hypotheses that the probability of assigning a guanaco group to a family group was constant. Moreover, sex-ratio estimation based on roadsurvey data was affected by survey conditions and could be biased.

The probability of classifying a guanaco group as a family group increased with survey date. This is coherent with the increasing fraction of lactating females with the progress of the postpartum season. This is also expected if juvenile detection, rather than adult behavior (i.e., presence of a vigilant male), were crucial for assigning groups to the familygroup category.

In agreement with our prediction, the probability of classifying a group as a family group decreased with time of day. This trend indicated that close to dusk there was a high probability of assigning a guanaco group to a male group. We propose two possible explanations: during dusk, an observer could have a lower chance to detect juveniles owing to poorer light conditions, or guanacos could tend to aggregate in larger herds at dusk (Puig and Videla 1995), and therefore observers might have a higher chance to detect larger groups and classify them rightly as male groups when juveniles are not present. Male groups seem to split into smaller groups at dawn as a feeding strategy, and aggregate at dusk as an antipredator strategy (Puig and Videla 1995).

The probability of classifying a group as a family group also declined with increasing group size. This trend is only marginally significant, and can be simply the result of bachelor males aggregating in herds larger than the average family group. Mean group size for male groups was larger than mean group size for family groups, in agreement with observations from other guanaco populations. Male groups have been estimated to be composed of 7-20 individuals and family groups of 5-13 individuals (Ortega and Franklin 1995; Puig and Videla 1995). On the other hand, observers could have a tendency to classify large groups without juveniles as male groups, and to consider smaller groups as undetermined. The mean size of our undetermined groups was 2.4 individuals (Table 1), a value much smaller than the mean size of male or family groups reported in the literature.

The probability of classifying a group as a family group decreased with the distance to the observer. Guanaco groups

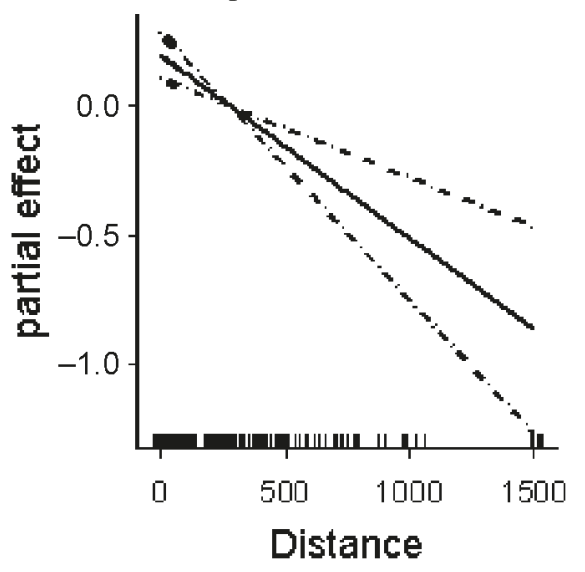

far from the observer may have had a higher tendency to be classified as male groups because juveniles could pass undetected. On the other hand, larger groups, that tended to be recorded as male groups, could be detected from longer distances, but this was to some extent considered independently in our model by including group size as a covariate. Guanaco social groups could show a nonrandom, differential distribution in relation to roads. For example, in other ungulates, family groups with juveniles may avoid proximity to roads (Fortin and Andruskiw 2003). However, Donadio and Buskirk (2006) did not find evidence that guanaco groups with juveniles would avoid roads, or areas with higher hunting pressure, more than other social groups. Indeed, we tended to observe family groups closer to roads than male groups (Fig. 3). Our results suggest that detectability of juveniles, and errors in group assignment, had a stronger effect than any potential road avoidance by family groups.

The effect of slope and observer on the probability of classifying a group as a family group was not significant. Topography may have not influenced juvenile detection, and observers seemed to be similarly trained and apparently used similar criteria to assign guanaco groups to social units.

The juvenile/female ratio declined with distance to the observer. This is consistent with the relative detectability of juveniles declining faster with distance to the observer than that of their mothers. The ratio increased with date, in agreement with the fact that more females had given birth as the season progressed. We observed a statistically weak trend for the juvenile/female ratio to decline with group size. This is inconsistent with the expectation that larger family groups live in more productive territories and should have, on average, higher juvenile/female ratios. However, this trend supports the idea that during road surveys we had a higher tendency to misclassify small family groups having a few or no juveniles. If it is necessary to see at least one juvenile to record a family group, this single juvenile will increase the ratio juvenile/female more in small than in large groups. The juvenile/female ratio did not show any particular trend with time of day. This suggests that the relationship between probability of classifying a group as a family group and time of day may be due more to the social behavior of male groups than to juvenile detectability.

Several factors apparently biased the estimation of gua- 
naco sex ratio from our road-survey data. The probability of classifying a group as a family group was affected by factors as survey date, time of day, and the distance to the observer. Although the literature indicates that one can tell between family groups and male groups on the basis of behavioral differences (Franklin 1983; Puig and Videla 1995), during road surveys these differences were not always so clear cut, and juvenile presence may be in practice the main criterion determining group assignment. We observed very few family groups without juveniles, which is inconsistent with a mean ratio of 0.46 juveniles/female in sightings classified as family groups. Most family groups without, or with undetected, juveniles were probably considered undetermined, or misclassified as male groups. Family groups were the only source for adult females because it was assumed that solitary animals were always males, and that true nonbreeding groups exclusively consisted of males. Groups composed only of females either have not been reported (Sosa and Sarasola 2005) or have been found at very low frequencies (Ortega and Franklin 1995; Marino and Baldi 2008). Ortega and Franklin (1995) reported that $<10 \%$ of females were found in family groups without a territorial male, this fact being attributed to the death of the territorial male, or to females moving with their offspring out of the male territory (Ortega and Franklin 1995; Puig and Videla 1995).

Guanaco road surveys can be useful for the estimation of population size and large-scale trends, habitat selection studies, and predictive distribution modeling (Travaini et al. 2007) if roads do no severely distort guanaco distribution. But caution should be taken if road surveys are used to estimate guanaco social structure or population sex ratio. We found that this method is not reliable to derive population social structure or sex ratio, and it could only be used to make relative comparisons among populations if survey conditions are properly standardized. Other methods are needed to study guanaco social groups or to estimate sex ratio at large spatial scales. Alternatives could be the use of samples of hunted or sheared guanacos for sex-ratio estimation, or capture-mark-recapture methods to study sex ratio and distribution of social groups.

\section{Acknowledgements}

This work was funded by the BBVA Foundation through a grant under the Conservation Biology Programme. Additional support was provided by Universidad Nacional de la Patagonia Austral, CONICET (PEI-6065), CONAE, and the Secretaría de Ambiente y Desarrollo Sustentable. J.P. was supported by a CONICET (Argentina) predoctoral fellowship. We thank Diego Procopio, Sonia Zapata, Rolando Martínez Peck, Martín Yaya, and Mara Brossman for field assistance, and Silvia Puig and Pablo D. Carmanchahi for their constructive criticism of an earlier draft of the manuscript.

\section{References}

Baldi, R., Albon, S.D., and Elston, D.A. 2001. Guanacos and sheep: evidence for continuing competition in arid Patagonia. Oecologia (Berl.), 129: 561-570. doi:10.1007/s004420100770.

Baldi, R., Pelliza-Sbriller, A., Elston, D.A., and Albon, S.D. 2004. High potential for competition between guanacos and sheep in
Patagonia. J. Wildl. Manage. 68(4): 924-938. doi:10.2193/0022541X(2004)068[0924:HPFCBG]2.0.CO;2.

Baldi, R., Carmanchahi, P., De Lamo, D., Failla, M., Ferrando, P., Funes, M., Puig, S., Rivero, S., and Von Thüngen, J. 2006. Conservación del guanaco en la Argentina. Propuesta para un plan nacional de manejo. In Manejo de Fauna Silvestre en la Argentina: Programas de uso sustentable. Edited by M.L. Bolkovic and D. Ramadori. Dirección de Fauna Silvestre, Secretaría de Ambiente y Desarrollo Sustentable, Buenos Aires. pp. 137-149. [In Spanish.]

Bank, M.S., Sarno, R.J., and Franklin, W.L. 2003. Spatial distribution of guanaco mating sites in southern Chile: conservation implications. Biol. Conserv. 112(3): 427-434. doi:10.1016/S00063207(02)00342-7.

Bonino, N. 1988. Censo de las poblaciones de guanaco (Lama guanicoe) de la Tierra del Fuego, Argentina: resultado del primer año de recuento. Comunicación técnica $\mathrm{N}^{\circ} 25$, Área de Recursos Naturales y Fauna, INTA, Centro Regional Patagonia Norte, Estación Experimental Agropecuaria Bariloche. [In Spanish.]

Cabrera, A.L. 1976. Regiones Fitogeográficas Argentinas. In Enciclopedia Argentina de agricultura y jardinería, Tomo II, Fascículo 1. Edited by ACME, Buenos Aires, Argentina. pp. 1-85. [In Spanish.]

Clutton-Brock, T.H. 1989. Mammalian mating systems. Proc R Soc Lond B Biol. Sci. 236(1285): 339-372. doi:10.1098/rspb.1989. 0027. PMID:2567517.

Clutton-Brock, T.H. 1991. The evolution of parental care. Princeton University Press, Princeton, N.J.

Clutton-Brock, T.H., and Iason, G.R. 1986. Sex ratio variation in mammals. Q. Rev. Biol. 61(3): 339-374. doi:10.1086/415033. PMID:3532167.

Clutton-Brock, T.H., Albon, S.D., and Guinness, N.D. 1982. Red deer: ecology and behavior of two sexes. The University of Chicago Press, Chicago.

Crawley, M.J. 2002. Statistical computing. John Wiley and Sons, Chichester, UK.

De Lamo, D., Garrido, J.L., and Kovacs, Z. 1982. Población y parámetros reproductivos del guanaco (Lama guanicoe). $10^{\circ} \mathrm{Re}-$ unión Argentina de Ecología, Mar del Plata, Argentina. pp. 123129. [In Spanish.]

Donadio, E., and Buskirk, S.W. 2006. Flight behavior in guanacos and vicuñas in areas with and without poaching in western $\mathrm{Ar}$ gentina. Biol. Conserv. 127(2): 139-145. doi:10.1016/j.biocon. 2005.08.004 .

Emlen, S.T., and Oring, L.W. 1977. Ecology, sexual selection, and the evolution of mating systems. Science (Washington, D.C.), 197(4300): 215-223. doi:10.1126/science.327542. PMID: 327542 .

Fortin, D., and Andruskiw, M. 2003. Behavioral response of freeranging bison to human disturbance. Wildl. Soc. Bull. 31: 804813.

Franklin, W.F. 1983. Contrasting socioecologies of South American's wild camelids: the vicuña and the guanaco. In Mammalian biology in South America. Edited by J.F. Eisenberg and D.G. Kleiman. American Society of Mammalogists, Provo, Utah. pp. 573-629.

Franklin, W.L., and Fritz, M.A. 1991. Sustained harvesting of the Patagonian guanaco: is it possible or too late? In Neotropical wildlife use and conservation. Edited by K. Redford and J. Robinson. The University of Chicago Press, Chicago. pp. 317-336.

Franklin, W.L., Bas, F., Bonacic, C.F., Cunazza, C., and Soto, N. 1997. Striving to manage Patagonia guanacos for sustained use in the grazing agroecosystems of southern Chile. Wildl. Soc. Bull. 25: 65-73. 
Hastie, T., and Tibshirani, R.J. 1990. Generalized additive models. Chapman and Hall, London.

Marino, A., and Baldi, R. 2008. Vigilance patterns of territorial guanacos (Lama guanicoe): the role of reproductive interests and predation risk. Ethology, 114(4): 413-423. doi:10.1111/j. 1439-0310.2008.01485_1.x.

MathSoft. 1999. S-Plus 2000: user's guide. Data Analysis Products Division, MathSoft Inc., Seattle, Wash.

Merino, M.L., and Cajal, C.J. 1993. Estructura social de la población de guanacos (Lama guanicoe Muller, 1776) en la costa norte de Península Mitre, Tierra del Fuego, Argentina. Stud. Neotrop. Fauna Environ. 28(3): 129-138. doi:10.1080/ 01650529309360897. [In Spanish.]

Ortega, I.M., and Franklin, W.L. 1995. Social organization, distribution and movements of a migratory guanaco population in the Chilean Patagonia. Rev. Chil. Hist. Nat. 68: 489-500.

Puig, S., and Videla, F. 1995. Comportamiento y organización social del guanaco. In Técnicas para el manejo del guanaco. Edited by S. Puig. International Union for Conservation of Nature, Gland, Switzerland. pp. 97-118. [In Spanish.]

Redford, K., and Eisenberg, J. 1992. Mammals of the Neotropics: the southern cone. Chile, Argentina, Uruguay and Paraguay. The University of Chicago Press, Chicago.

Rial, P. 2001. Grandes unidades de paisaje. In Ganadería ovina sustentable en la Patagonia Austral. Tecnología de manejo extensivo. Edited by P. Borreli and G. Oliva. Convenio INTAUNPA-CAP. Río Gallegos, Santa Cruz, Argentina. pp. 22-40. [In Spanish.]
Saba, S., de Lamo, D., and Puig, S. 1995. Dinámica poblacional del guanaco. In Técnicas para el manejo del guanaco. Edited by S. Puig. International Union for the Conservation of Nature, Gland, Switzerland. pp. 71-84. [In Spanish.]

Sarno, R.J., and Franklin, W.L. 1999. Maternal expenditure in the polygynous and monomorphic guanaco: suckling behavior, reproductive effort, year variation, and influence on juvenile survival. Behav. Ecol. 10(1): 41-47. doi:10.1093/beheco/10.1.41.

Sarno, R.J., Bank, M.S., Stern, H.S., and Franklin, W.L. 2003. Forced dispersal of juvenile guanacos (Lama guanicoe): causes, variation, and fates of individuals dispersing at different times. Behav. Ecol. Sociobiol. 54(1): 22-29. doi:10.1007/s00265-0030604-5.

Soriano, A. 1956. Los distritos florísticos de la Provincia Patagónica. Rev. Argent. Invest. Agr. (Buenos Aires), 10: 323-347.

Sosa, R.A., and Sarasola, J.H. 2005. Habitat use and social structure of an isolated population of guanacos (Lama guanicoe) in the Monte Desert, Argentina. Eur. J. Wildl. Res. 51(3): 207209. doi:10.1007/s10344-005-0105-0.

Travaini, A., Bustamante, J., Rodríguez, A., Zapata, S., Procopio, D., Pedrana, J., and Martínez-Peck, R. 2007. An integrated framework to map animal distributions in large and remote regions. Divers. Distrib. 13(3): 289-298. doi:10.1111/j.1472-4642.2007. 00338.x.

Young, J.K., and Franklin, W.L. 2004. Activity budget patterns in family-group and solitary territorial male guanacos. Rev. Chil. Hist. Nat. 77(4): 617-625. doi:10.4067/S0716-078X2004000400005. 